\title{
Studi Kualitas Energi Listrik Gedung Fakultas Teknik Universitas Bangka Belitung
}

\author{
Asmar $^{1}$, Wahri Sunanda ${ }^{2 *}$ \\ ${ }^{1,2}$ Jurusan Teknik Elektro, Fakultas Teknik, Universitas Bangka Belitung, Bangka \\ *Koresponden email: sunandawahri@gmail.com
}

Diterima: 30 Maret 2021

Disetujui: 26 April 2021

\begin{abstract}
One of the performances of the electric power system can be seen from the quality of electrical energy. In this study, the measurement of the quality of electrical energy was carried out using a power quality meter to obtain the values of current, voltage, frequency, total current harmonic distortion and total voltage harmonic distortion in the building of the Faculty of Engineering, Universitas Bangka Belitung. From measurements on the 3 existing buildings, it was found that the measured voltage value range was still at $+5 \%$ to $-10 \%$ of the 220 Volt secondary distribution voltage value and the frequency value was still in the range of $49.5 \mathrm{~Hz}$ to $50.5 \mathrm{~Hz}$. The total value of voltage harmonic distortion is still below the required value, but the total value of current harmonic distortion is above the required value.
\end{abstract}

Keywords: quality of electrical energy, current, voltage, frequency, harmonic

\begin{abstract}
Abstrak
Kinerja sistem tenaga listrik salah satunya dapat dilihat dari kualitas energi listrik. Pada penelitian ini dilakukan pengukuran kualitas energi listrik menggunakan power quality meter untuk mendapatkan nilai arus, tegangan, frekuensi, total distorsi harmonisa arus dan total distorsi harmonisa tegangan pada gedung Fakultas Teknik Universitas Bangka Belitung. Dari pengukuran pada 3 gedung yang ada didapat bahwa rentang nilai tegangan yang terukur masih berada pada $+5 \%$ hingga $-10 \%$ dari nilai tegangan distribusi sekunder 220 Volt serta nilai frekuensi masih berada pada rentang 49,5 Hz hingga 50,5 Hz. Nilai total distorsi harmonisa tegangan masih di bawah nilai yang dipersyaratkan, namun nilai total distorsi harmonisa arus berada di atas nilai yang dipersyaratkan.
\end{abstract}

Kata Kunci: kualitas energi listrik, arus, tegangan, frekuensi, harmonisa

\section{Pendahuluan}

Kualitas energi listrik menjadi hal yang penting untuk diperhatikan, karena berkenaan dengan tegangan, arus, deviasi frekuensi yang dapat menyebabkan kegagalan pada pengoperasian sistem tenaga listrik [1]. Hal lain yang perlu juga diperhatikan terkait total distorsi harmonisa arus dan total distorsi harmonisa tegangan [2] berdasarkan IEEE 519:1992 [3] dan Peraturan Menteri Energi dan Sumber Daya Mineral No 4 Tahun 2009 tentang Aturan Distribusi Tenaga Listrik [4].

Bangunan gedung perkuliahan merupakan salah satu fasilitas yang terdiri atas banyak beban peralatan listrik. Selain dimanfaatkan oleh mahasiswa secara langsung dalam perkuliahan dan praktikum, juga bagi tenaga kependidikan dan dosen yang bekerja. Walaupun jam puncak aktivitas berada pada pagi hingga siang hari, namun tentunya menjadi perhatian terkait layanan kontinuitas dengan kualitas yang baik dari listrik yang mengalir agar perkuliahan dan kinerja dapat berjalan dengan baik [5].

Oleh karenanya frekuensi harus mempunyai rentang $49,5 \mathrm{~Hz}-50,5 \mathrm{~Hz}$ untuk frekuensi nominal sistem $50 \mathrm{~Hz}$, tegangan sistem distribusi harus berada pada batas kondisi normal yakni maksimal $+5 \%$ dan minimal $-10 \%$ dari tegangan nominal. Sedangkan untuk total distorsi harmonik dapat dilihat pada Tabel 1 dan Tabel 2 [4]. Tegangan, arus, frekuensi, total distorsi harmonisa arus dan total distorsi harmonisa tegangan menjadi hal penting yang harus dievaluasi dan diperhatikan selalu agar kinerja dalam bidang ketenagalistrikan dapat meningkat dalam memberikan pelayanan kepada masyarakat [6]. 
Tabel 1. Batas maksimum distosi harmonisa tegangan [4]

\begin{tabular}{|c|c|c|c|c|c|c|}
\hline \multicolumn{4}{|c|}{ Distorsi Harmonisa Tegangan Individu (\%) } & \multicolumn{3}{|c|}{ Distorsi Harmonisa Tegangan Total (\%) } \\
\hline \multicolumn{4}{|c|}{3} & \multicolumn{3}{|c|}{5} \\
\hline \multicolumn{7}{|c|}{ Tabel 2. Batas maksimum distorsi harmonisa arus [4] } \\
\hline $\begin{array}{c}\text { Harmonisa } \\
\text { ganjil, h }\end{array}$ & $\mathrm{H}<11$ & $11 \leq \mathrm{h}<17$ & $17 \leq h<23$ & $23 \leq \mathrm{h}<35$ & $35 \leq \mathrm{h}<$ & TDD \\
\hline $\begin{array}{c}\text { Distorsi } \\
\text { Harmonisa } \\
\text { Arus (\%) }\end{array}$ & 4 & 2 & 1,5 & 0,6 & 0,3 & 5,0 \\
\hline
\end{tabular}

Penelitian terkait kualitas daya listrik pada bangunan kampus pada beberapa bangunan kampus diantaranya; di Universitas Negeri Medan [5], Universitas PGRI Semarang [7] , Politeknik Negeri Jakarta [8], Politeknik Enjinering Indorama [9], Politeknik Negeri Ujung Pandang [10], Fakultas Teknik Universitas Lampung [11], Universitas Tadulako [12], FMIPA UPI [13] dan Fakultas Kedokteran Universitas Udayana [14]. Dalam kaitan, penelitian ini bertujuan untuk melakukan pengukuran terhadap arus, tegangan, frekuensi, total distorsi harmonisa arus dan total distorsi harmonisa tegangan pada 3 gedung di Fakultas Teknik Universitas Bangka Belitung. Hal ini merupakan upaya pencegahan terhadap permasalahan kelistrikan yang mungkin akan muncul pada bangunan gedung perkuliahan di Fakultas Teknik Universitas Bangka Belitung yang merupakan bagian dari 12 gedung utama yang ada di Universitas Bangka Belitung yang saat ini mendapat pasokan daya 690 kVA dari PLN[15].

\section{Metode Penelitian}

Penelitian dilakukan dengan pengukuran menggunakan power quality meter pada 3 panel utama yang tersedia di Gedung Dharma Pendidikan, Gedung Dharma Penelitian dan Gedung Dharma Pengabdian di Fakultas Teknik Universitas Bangka Belitung. Parameter yang didapatkan dari pengukuran berupa arus, tegangan, frekuensi, total harmonisa distorsi arus (THDi) dan total harmonisa distorsi tegangan (THDv). Pada pengukuran yang dilakukan, semua beban peralatan yang tersedia dalam keadaan dinyalakan, sehingga dapat memberikan deskripsi total dari penggunaan dan kualitas energi listrik pada 3 gedung di Fakultas Teknik Universitas Bangka Belitung.

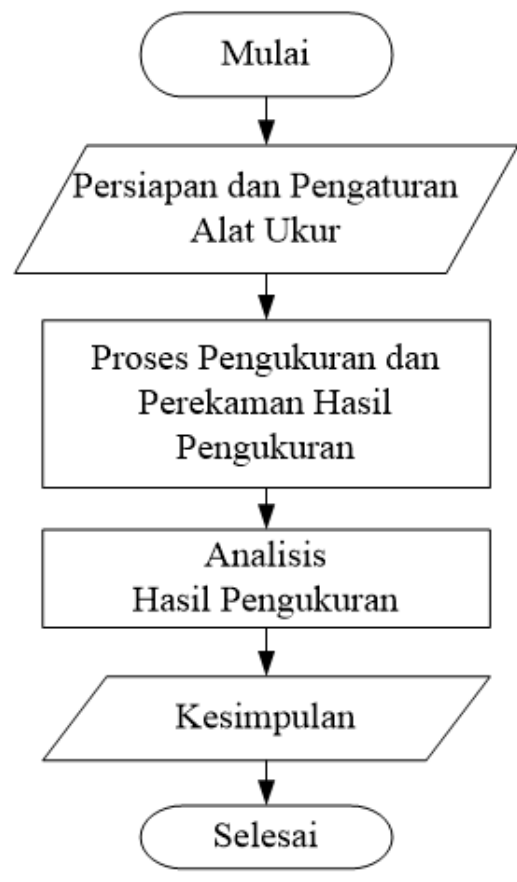

Gambar 1. Diagram alir penelitian

Diagram alir penelitian secara lengkap ditunjukkan pada Gambar 1 yang diawali dengan memastikan semua peralatan listrik dalam kondisi menyala dan pengaturan alat ukur yang akan digunakan. Alat ukur yang digunakan adalah PowerQ4 Plus MI 2792. Alat ukur ini dapat mengukur berbagai parameter kelistrikan diantaranya tegangan, arus, frekuensi, daya, dan harmonisa. Selain itu, alat 
ukur juga dapat merekam hasil pengukuran sesuai dengan pengaturan waktu yang diberikan. Setelah persiapan alat ukur dan semua beban dinyalakan, langkah berikutnya adalah melakukan proses pengukuran. Clamp arus listrik dan probe tegangan dihubungkan pada panel listrik. Alat ukur akan merekam hasil pengukuran selama 10 menit. Data hasil pengukuran pada alat ukur diunduh untuk dianalisis dan dibandingkan dengan Peraturan Menteri Energi dan Sumber Daya Mineral No 4 Tahun 2009 tentang Aturan Distribusi Tenaga Listrik.

\section{Hasil dan Pembahasan}

Pengukuran kualitas energi listrik yang dilakukan di Gedung Dharma Pendidikan dilakukan pada pukul 10.48 - 10.58 WIB dengan semua peralatan yang ada di dalam gedung dalam kondisi nyala. Dari hasil pengukuran menggunakan power quality meter didapat hasil pada Tabel 3 dan Tabel 4.

Tabel 3. Hasil pengukuran tegangan, arus dan frekuensi Gedung Dharma Pendidikan

\begin{tabular}{ccccccc}
\hline $\begin{array}{c}\text { U1(AvgOn) } \\
{[\mathrm{V}]}\end{array}$ & $\begin{array}{c}\mathrm{U} 2(\mathrm{AvgOn}) \\
{[\mathrm{V}]}\end{array}$ & $\begin{array}{c}\mathrm{U3}(\mathrm{AvgOn}) \\
{[\mathrm{V}]}\end{array}$ & $\begin{array}{c}\mathrm{I} 1(\mathrm{AvgOn}) \\
{[\mathrm{A}]}\end{array}$ & $\begin{array}{c}\mathrm{I} 2(\mathrm{AvgOn}) \\
{[\mathrm{A}]}\end{array}$ & $\begin{array}{c}\text { I3(AvgOn) } \\
{[\mathrm{A}]}\end{array}$ & $\begin{array}{c}\mathrm{f}(\mathrm{AvgOn}) \\
{[\mathrm{Hz}]}\end{array}$ \\
\hline 221,39 & 228,89 & 198,60 & 38,79 & 34,59 & 83,19 & 50,09 \\
220,10 & 227,39 & 201,39 & 39,79 & 35,40 & 78,80 & 50,09 \\
220,30 & 226,80 & 200,60 & 40,5 & 36,79 & 80,59 & 50,09 \\
218,60 & 226,80 & 200,39 & 47,79 & 37,90 & 84,80 & 50,08 \\
218,10 & 228 & 197,69 & 51,29 & 39,29 & 89 & 50,09 \\
210,80 & 219,89 & 221,19 & 53,90 & 47,5 & 44,59 & 50,04 \\
210 & 219 & 222 & 55,59 & 49,59 & 44,40 & 49,97 \\
211,30 & 219,80 & 218,5 & 55,5 & 50 & 53,09 & 50,02 \\
216 & 222 & 206,30 & 55,29 & 50,70 & 74,80 & 50,08 \\
218,30 & 224,10 & 197,69 & 55,20 & 50,20 & 84,80 & 50,03 \\
\hline
\end{tabular}

Dari Tabel 3 terlihat bahwa nilai tegangan pada U1 210,8 Volt sampai dengan 221,39 Volt, untuk U2 219,8 Volt sampai dengan 228,89 Volt, sedangkan U3 197,69 Volt sampai dengan 221,19 Volt. Sedangkan untuk arus terlihat, bawah I1 38,79 Ampere sampai dengan 55,59 Ampere, untuk I2 34,59 sampai dengan 50,70 Ampere, dan untuk I3 44,40 Ampere sampai dengan 84,80 Ampere.

Tabel 4. Hasil pengukuran total harmonisa tegangan dan arus Gedung Dharma Pendidikan

\begin{tabular}{cccccc}
\hline THD & THD & THD & THD & THD & THD \\
U1(AvgOn) & U2(AvgOn) & U3(AvgOn) & I1(AvgOn) & I2(AvgOn) & $\begin{array}{c}\text { I3(AvgOn) } \\
{[\%]}\end{array}$ \\
{$[\%]$} & {$[\%]$} & {$[\%]$} & $9 \%]$ \\
\hline 1,9 & 1,7 & 1,8 & 7,4 & 9 & 3,5 \\
1,9 & 1,7 & 1,8 & 7,6 & 9,2 & 3,7 \\
1,9 & 1,7 & 1,8 & 7,1 & 8,8 & 3,4 \\
1,9 & 1,7 & 1,8 & 5,9 & 8,7 & 3,4 \\
1,9 & 1,7 & 1,8 & 5,9 & 9,2 & 3,3 \\
2 & 1,8 & 1,9 & 5,4 & 7,3 & 6,3 \\
2 & 1,8 & 1,9 & 5,4 & 6,6 & 6,3 \\
1,9 & 1,7 & 1,8 & 5,4 & 6,2 & 5,5 \\
1,9 & 1,6 & 1,7 & 5,9 & 6,3 & 3,9 \\
1,9 & 1,6 & 1,8 & 5,5 & 6,5 & 3,2 \\
\hline
\end{tabular}

Pada Tabel 3 dapat dilihat bahwa untuk frekuensi berada pada 49,97 - 50,09 Hz. Dari rentang nilai tegangan pada tiap fase pada Tabel 3, terlihat bahwa nilai tegangan yang terukur masih berada pada $+5 \%$ hingga $-10 \%$ dari nilai tegangan distribusi sekunder 220 Volt dan nilai frekuensi juga masih berada 49,5 hingga $50,5 \mathrm{~Hz}$ sesuai yang dipersyaratkan pada Peraturan Menteri Energi dan Sumber Daya Mineral No 4 Tahun 2009 tentang Aturan Distribusi Tenaga Listrik.

Sedangkan pada Tabel 4 terlihat bahwa nilai total distorsi harmonisa tegangan (THDv) masih berada di bawah batas maksimum yang dipersyaratkan, namun tidak dengan nilat total distorsi harmonisa arus (THDi) yang sudah berada di atas batas maksimum sesuai yang diatur Peraturan Menteri Energi dan Sumber Daya Mineral No 4 Tahun 2009 tentang Aturan Distribusi Tenaga Listrik. 
Tabel 5. Hasil pengukuran tegangan, arus dan frekuensi Gedung Dharma Penelitian

\begin{tabular}{cccccc}
\hline $\begin{array}{c}\text { U1(AvgOn) } \\
{[\mathrm{V}]}\end{array}$ & $\begin{array}{c}\text { U2(AvgOn) } \\
{[\mathrm{V}]}\end{array}$ & $\begin{array}{c}\text { U3(AvgOn) } \\
{[\mathrm{V}]}\end{array}$ & $\begin{array}{c}\text { I1(AvgOn) } \\
{[\mathrm{A}]}\end{array}$ & $\begin{array}{c}\text { I2(AvgOn) } \\
{[\mathrm{A}]}\end{array}$ & $\begin{array}{c}\text { I3(AvgOn) } \\
{[\mathrm{A}]}\end{array}$ \\
\hline 217,10 & 225,19 & 207,60 & 70,69 & 38,09 & 69,59 \\
216,5 & 225,80 & 208,30 & 70,69 & 38,20 & 67,80 \\
216,19 & 226,5 & 207,5 & 70,80 & 37,40 & 69,09 \\
216,19 & 226,19 & 206,5 & 70,80 & 36,90 & 69,19 \\
216,5 & 226,10 & 205,19 & 71,59 & 36,70 & 71,30 \\
215,60 & 225,30 & 205,10 & 72,5 & 36,79 & 70,69 \\
213,60 & 226,60 & 203,69 & 72,80 & 36,70 & 74,59 \\
213,89 & 227 & 201,69 & 72,90 & 36,90 & 77,90 \\
215,39 & 228,19 & 200,19 & 67,90 & 36,90 & 80,69 \\
216,39 & 227,80 & 200,19 & 64,59 & 37,20 & 79,59 \\
\hline
\end{tabular}

Pada Tabel 5 merupakan hasil pengukuran di Gedung Dharma Penelitian pada pukul 10.48-10.58 WIB. Peralatan listrik yang ada pada lantai 1 dan lantai 2 dalam keadaan dinyalakan. Terlihat bahwa hasil pengukuran tegangan pada fase U1, fase U2 dan fase U3 masih berada pada batas maksimal $+5 \%$ hingga batas minimal $-10 \%$ dari tegangan distribusi sekunder 220 Volt. Untuk arus pada fase U1 berada pada 64,59 - 72,9 Ampere, arus pada fase U1 berada pada 36,70 - 38, 20 Ampere dan arus pada fase U3 67,8 80,69 Ampere.

Tabel 6. Hasil pengukuran total harmonisa tegangan dan arus Gedung Dharma Penelitian

\begin{tabular}{|c|c|c|c|c|c|c|}
\hline $\begin{array}{c}\mathrm{f}(\mathrm{AvgOn}) \\
{[\mathrm{Hz}]}\end{array}$ & $\begin{array}{c}\text { THD } \\
\text { U1(AvgOn) } \\
{[\%]}\end{array}$ & $\begin{array}{c}\text { THD } \\
\text { U2(AvgOn) } \\
{[\%]} \\
\end{array}$ & $\begin{array}{c}\text { THD } \\
\text { U3(AvgOn) } \\
{[\%]}\end{array}$ & $\begin{array}{c}\text { THD } \\
\text { I1(AvgOn) } \\
{[\%]} \\
\end{array}$ & $\begin{array}{c}\text { THD } \\
\text { I2(AvgOn) } \\
{[\%]}\end{array}$ & $\begin{array}{c}\text { THD } \\
\text { I3(AvgOn) } \\
{[\%]}\end{array}$ \\
\hline 50,09 & 2 & 1,7 & 1,9 & 5,9 & 8,9 & 4,3 \\
\hline 50,11 & 2 & 1,7 & 2 & 5,7 & 9,1 & 4,4 \\
\hline 50,11 & 2 & 1,8 & 2 & 5,8 & 8,7 & 4,4 \\
\hline 49,99 & 2 & 1,8 & 2 & 5,8 & 9,6 & 4,4 \\
\hline 50 & 2 & 1,8 & 2 & 5,8 & 9,2 & 4,2 \\
\hline 50,08 & 2,1 & 1,9 & 2 & 5,8 & 8,8 & 4,5 \\
\hline 50,10 & 2,2 & 1,9 & 2,1 & 5,6 & 9,2 & 4,3 \\
\hline 50,07 & 2,1 & 1,9 & 2,1 & 5,6 & 9,6 & 4,5 \\
\hline 50,08 & 2,1 & 1,9 & 2,1 & 5,9 & 9,2 & 4,5 \\
\hline 50,02 & 2,2 & 2 & 2,1 & 6,3 & 9,2 & 4,4 \\
\hline
\end{tabular}

Dari Tabel 6 terlihat bahwa nilai frekuensi terukur di Gedung Dharma Penelitian masih berada pada batas frekuensi yang dipersyaratkan. Untuk nilai total distorsi harmonisa tegangan (THDv) masih berada di bawah batas yang dipersyaratkan. Namun kondisi berbeda dengan total distorsi harmonisa arus (THDi) yang berada di atas batas yang dipersyaratkan Peraturan Menteri Energi dan Sumber Daya Mineral No 4 Tahun 2009 tentang Aturan Distribusi Tenaga Listrik.

Pada Tabel 7 merupakan pengukuran yang dilakukan pada pukul 10.48-10.58 WIB di Gedung Dharma Pengabdian dengan terlebih dahulu memastikan kondisi peralatan listrik pada 2 lantai dalam keadaan dinyalakan. Nilai tegangan terukur pada fase U1, fase U2 dan fase U3 masih berada dalam rentang 198 - 231 Volt sesuai yang dipersyaratkan. Sedangkan nilai arus terukur pada fase U1 42,5 - 43,9 Ampere, nilai arus terukur pada fase U2 53,8 - 62,4 Ampere serta arus terukur pada fase U3 45,5 - 50,5 Ampere.

Untuk Tabel 8 merupakan hasil pengukuran frekuensi, total distorsi harmonisa tegangan dan total distorsi harmonisa arus di Gedung Dharma Pengabdian. Nilai frekuensi terukur masih berada pada 49,5 $50,5 \mathrm{~Hz}$ sesuai yang dipersyaratkan, begitu juga dengan nilai total distorsi harmonisa tegangan. Namun nilai total distorsi harmonisa arus berada di atas yang dipersyaratkan Peraturan Menteri Energi dan Sumber Daya Mineral No 4 Tahun 2009 tentang Aturan Distribusi Tenaga Listrik. 
Tabel 7. Hasil pengukuran tegangan, arus dan frekuensi Gedung Dharma Pengabdian

\begin{tabular}{cccccc}
\hline $\begin{array}{c}\text { U1(AvgOn) } \\
{[\mathrm{V}]}\end{array}$ & $\begin{array}{c}\text { U2(AvgOn) } \\
{[\mathrm{V}]}\end{array}$ & $\begin{array}{c}\text { U3(AvgOn) } \\
{[\mathrm{V}]}\end{array}$ & $\begin{array}{c}\text { I1(AvgOn) } \\
{[\mathrm{A}]}\end{array}$ & $\begin{array}{c}\text { I2(AvgOn) } \\
{[\mathrm{A}]}\end{array}$ & $\begin{array}{c}\text { I3(AvgOn) } \\
{[\mathrm{A}]}\end{array}$ \\
\hline 213,30 & 217,60 & 219,90 & 43,70 & 55,50 & 45,80 \\
213,80 & 217,60 & 220,50 & 43,70 & 55,80 & 45,80 \\
213,40 & 218,80 & 221,30 & 43,60 & 54,00 & 45,90 \\
212,90 & 221,90 & 220,90 & 43,90 & 53,80 & 45,90 \\
215,00 & 219,30 & 221,80 & 43,70 & 59,00 & 45,60 \\
216,00 & 216,90 & 223,70 & 43,60 & 62,10 & 45,50 \\
216,90 & 216,40 & 224,60 & 43,50 & 62,40 & 45,80 \\
217,80 & 217,70 & 222,20 & 43,30 & 61,40 & 50,50 \\
217,10 & 218,90 & 222,60 & 42,70 & 62,10 & 50,10 \\
217,60 & 219,00 & 221,80 & 42,50 & 62,10 & 50,20 \\
\hline
\end{tabular}

Tabel 8. Hasil pengukuran total harmonisa tegangan dan arus Gedung Dharma Pengabdian

\begin{tabular}{|c|c|c|c|c|c|c|}
\hline $\begin{array}{c}\mathrm{f}(\mathrm{AvgOn}) \\
{[\mathrm{Hz}]}\end{array}$ & $\begin{array}{c}\text { THD } \\
\text { U1(AvgOn) } \\
{[\%]}\end{array}$ & $\begin{array}{c}\text { THD } \\
\text { U2(AvgOn) } \\
{[\%]}\end{array}$ & $\begin{array}{c}\text { THD } \\
\text { U3(AvgOn) } \\
{[\%]}\end{array}$ & $\begin{array}{c}\text { THD } \\
\text { I1(AvgOn) } \\
{[\%]}\end{array}$ & $\begin{array}{c}\text { THD } \\
\text { I2(AvgOn) } \\
{[\%]}\end{array}$ & $\begin{array}{c}\text { THD } \\
\text { I3(AvgOn) } \\
{[\%]}\end{array}$ \\
\hline 50,04 & 2,1 & 2 & 2,1 & 6,3 & 6,1 & 6,1 \\
\hline 50,02 & 2,1 & 1,9 & 2 & 6,4 & 6,2 & 6,1 \\
\hline 50,02 & 2,1 & 1,9 & 2 & 6,2 & 6,2 & 6 \\
\hline 50,07 & 2,1 & 1,9 & 2 & 6 & 6,3 & 6,2 \\
\hline 50,07 & 2 & 1,8 & 2 & 6,5 & 6,1 & 6,4 \\
\hline 50,05 & 2 & 1,8 & 2 & 6,3 & 5,7 & 6,1 \\
\hline 50,05 & 2 & 1,8 & 2 & 6,2 & 5,5 & 6,2 \\
\hline 50,08 & 2 & 1,7 & 1,9 & 6,5 & 5,7 & 6 \\
\hline 50,08 & 1,9 & 1,7 & 1,9 & 6,7 & 5,6 & 6 \\
\hline 50,11 & 2 & 1,7 & 1,9 & 6,4 & 5,7 & 5,8 \\
\hline
\end{tabular}

Dari pengukuran yang dilakukan pada periode waktu yang sama di 3 gedung Fakultas Teknik Universitas Bangka Belitung, beberapa parameter masih berada dalam ambang batas yang dipersyaratkan Peraturan Menteri Energi dan Sumber Daya Mineral No 4 Tahun 2009 tentang Aturan Distribusi Tenaga Listrik, yakni tegangan, frekuensi dan total distorsi harmonisa tegangan. Namun total distorsi harmonisa arus perlu mendapatkan perhatian, begitupun dengan kesetimbangan arus pada tiap fase, sehingga beberapa kejadian yang mungkin dapat terjadi dikarenakan oleh faktor teknis kelistrikan dapat diantisipasi.

\section{Kesimpulan}

Kualitas energi listrik di Fakultas Teknik Universitas Bangka Belitung diantaranya dipantau melalui nilai arus, tegangan, frekuensi, total distorsi harmonisa tegangan dan total distorsi harmonisa arus yang diukur pada periode waktu yang sama. Dari pengukuran yang dilakukan ketika beban peralatan dinyalakan bersamaan, dapat terlihat bahwa nilai tegangan, frekuensi dan total distorsi harmonisa tegangan di Fakultas Teknik Universitas Bangka Belitung masih berada dalam ambang batas yang dipersyaratkan, namun nilai total distorsi harmonisa arus berada di atas ambang yang dipersyaratkan pada Peraturan Menteri Energi dan Sumber Daya Mineral No 4 Tahun 2009 tentang Aturan Distribusi Tenaga Listrik.

\section{Daftar Pustaka}

[1] A.W .Hasanah, T. Koerniawan, and Y.Yuliansyah, "Kajian Kualitas Daya Listrik PLTS Sistem OffGrid Di STT-PLN," Energi \& Kelistrikan, vol. 10 (2), pp.93-101. 2018.

[2] H.M. Naibaho, A. Warsito, and S. Handoko, "Peningkatan Kualitas Daya Listrik Dengan Menggunakan Bank Kapasitor Dan Filter Pada Kaji Station PT. MEDCO E\&P," Transient: Jurnal Ilmiah Teknik Elektro, vol. 5(3), pp.395-402. 2017.

[3] I.. F II, "IEEE recommended practices and requirements for harmonic control in electrical power systems," New York, NY, USA, pp.1-1. 1993 
[4] Departemen Energi dan Sumber Daya Mineral Republik Indonesia, Peraturan Menteri Energi Sumber dan Sumber Daya Mineral No 4 Tahun 2009 tentang Aturan Distribusi Tenaga Listrik. Jakarta, 2009.

[5] A.S. Sutopo, M.M. Mustamam, and M.A. Affandi, "Analisis Gangguan Kualitas Daya Sistem Tenaga Listrik Di Universitas Negeri Medan," Jurnal Pendidikan Teknologi dan Kejuruan, vol. 20(2). 2018.

[6] Y. Suryanto, "Analysis of Economic Regulations of National Electrical Systems," Jurnal Perencanaan Pembangunan: The Indonesian Journal of Development Planning, vol. 1(1), pp.4658. 2017.

[7] A. Kusmantoro, and A. Nuwolo, "Identifikasi Kualitas Daya Listrik Gedung Universitas PGRI Semarang," Prosiding SNST Fakultas Teknik, 1(1). 2015

[8] K. Kusnadi, and A.D. Aji, "Kualitas Daya Pada Instalasi Listrik Dengan Beban Non Linier (Studi Kasus Di Gedung Bengkel Listrik Politeknik Negeri Jakarta)," Jurnal Poli-Teknologi, vol. 15(2). 2016.

[9] A . Suryadi, "Studi Harmonisa Arus dan Tegangan Listrik pada Kampus Politeknik Enjinering Indorama," SINERGI, vol. 20(3), pp.213-222. 2016.

[10] A.R. Ashar, "Analisis Kualitas Daya Listrik Pada Gedung Teknik Elektro Kampus 2 Politeknik Negeri Ujung Pandang," In Seminar Nasional Hasil Penelitian \& Pengabdian Kepada Masyarakat (SNP2M). 2018

[11] D. Despa, G.F Nama, T. Septiana, and M.B. Saputra, "Audit Energi Listrik Berbasis Hasil Pengukuran Dan Monitoring Besaran Listrik Pada Gedung A Fakultas Teknik Unila," Electrician, vol. 15(1), pp. 33-38. 2021.

[12] B. Mukhlis, "Evaluasi penggunaan listrik pada bangunan gedung di lingkungan universitas tadulako".. In FORISTEK: Forum Teknik Elektro dan Teknologi Informasi, Vol. 1, No. 1, 2011.

[13] Y. Mulyadi, A. Rizki, and S. Sumarto, "Analisis Audit Energi untuk Pencapaian Efisiensi Penggunaan Energi di Gedung JICA FPMIPA Universitas Pendidikan Indonesia," electrans, vol. 12(1), pp. 81-88, 2013.

[14] R.S Hartati, I. N. S. Kumara, "Pengelolaan Energi Listrik Pada Gedung Fakultas Kedokteran Universitas Udayana Kampus Sudirman Denpasar," Majalah Ilmiah Teknologi Elektro, Vol. 11(2), .2012 .

[15] W. Sunanda, "Profil Beban pada Sistem Kelistrikan Universitas Bangka Belitung," Jurnal Ecotipe (Electronic, Control, Telecommunication, Information, and Power Engineering), vol. 4(1), pp. 1-6. 2017. 